\title{
ЙОДОДЕФИЦИТНЫЕ ЗАБОЛЕВАНИЯ: ТЕКУЩЕЕ СОСТОЯНИЕ ПРОБЛЕМЫ В РЕСПУБЛИКЕ KPЫM
}

'Трошина Е.А., 'Абдулхабирова Ф.М., 'Маколина Н.П., 'Сенюшкина Е.С., 'Пронина Л.О., 'Никанкина Л.В., 'Малышева Н.М., ${ }^{2}$ Репинская И.Н., ${ }^{2}$ Дивинская В.А.

'ФГБУ «НМИЦ эндокринологии» Минздрава России, Москва, Россия

${ }^{2}$ Министерство здравоохранения Брянской области, Брянск, Россия

ЦЕЛЬ: оценка йодной обеспеченности населения Республики Крым.

МАТЕРИАЛЫ И МЕТОДЫ: исследование проводилось в 2020 г. в общеобразовательных школах четырех районов Республики Крым - в гг. Симферополь, Белогорск, Бахчисарай и Саки. Объем исследования - 356 детей допубертатного возраста (8-10 лет), всем были выполнены: сбор анамнеза и измерение антропометрических показателей (рост, вес), осмотр врача-эндокринолога с пальпацией щитовидной железы (ЩЖ), ультразвуковое исследование (УЗИ) ЩЖ, получение разовых порций мочи и образцов пищевой поваренной соли, которая ежедневно используется в питании в их семьях. УзИ ЩЖ выполнялось в положении лежа с использованием портативного ультразвукового аппарата LOGIQе (China) с мультичастотным линейным датчиком 10-15 МГц. Определение концентрации йода в разовых образцах мочи

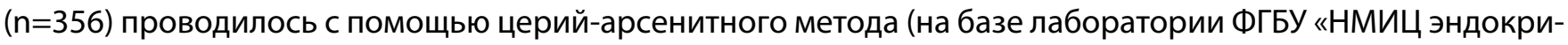
нологии» Минздрава России). Качественное исследование на наличие йодата калия в образцах пищевой поваренной соли ( $\mathrm{n}=203)$ осуществлялось на месте экспресс-методом. От всех родителей/опекунов детей получены информированные согласия на проведение обследования и обработку персональных данных. Разрешение локального этического комитета ФГБУ «НМИЦ эндокринологии» Минздрава России получено 25 марта 2020 г., №5.

РЕЗУЛЬТАТЫ: по результатам обследования 356 детей младшего школьного возраста медианная концентрация йода в моче составила 97 мкг/л и варьировала от 78 до 98 мкг/л. Доля проб мочи со сниженной концентрацией йода составила 51,2\%. Доля использования в семьях школьников йодированной соли составила 12,3\% (диапазон значений от 10 до 15\%). Средняя частота распространенности зоба у детей по данным УЗИ - 9,5\% (диапазон значений от 1,7 до 16,3\%).

\section{выводы:}

1. Показатель медианной концентрации йода в моче свидетельствует о недостаточной йодной обеспеченности населения Республики Крым.

2. Распространенность зоба у детей младшего школьного возраста по данным УзИ щЖ соответствует легкой степени тяжести йодного дефицита в регионе.

3. Доля домохозяйств, использующих йодированную соль, крайне низкая и составляет $12,3 \%$, что не соответствует рекомендациям ВО3 для регионов с природным дефицитом йода (от $90 \%$ и более).

КЛЮЧЕВЫЕ СЛОВА: йодный дефичит, зоб, йододефичитные заболевания, йодированная соль. 